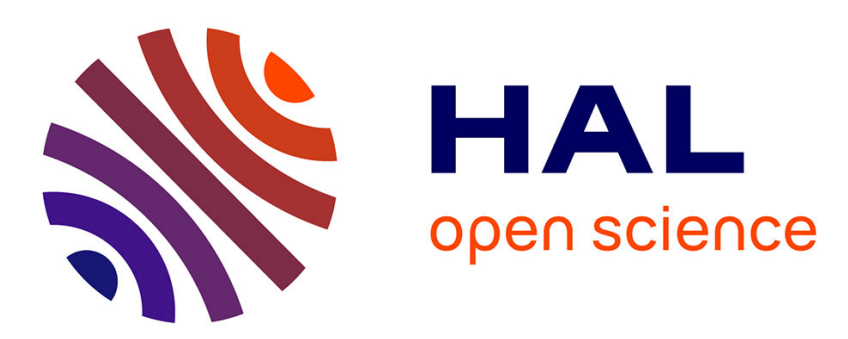

\title{
A new electrochemical cell with a uniformly accessible electrode to study fast catalytic reactions
}

Mariam Fadel, Daurelle Jean-Vincent, Vincent Fourmond, Jérôme Vicente

\section{To cite this version:}

Mariam Fadel, Daurelle Jean-Vincent, Vincent Fourmond, Jérôme Vicente. A new electrochemical cell with a uniformly accessible electrode to study fast catalytic reactions. Physical Chemistry Chemical Physics, 2019, 21 (23), pp.12360-12371. 10.1039/c9cp01487j . hal-02308533

\section{HAL Id: hal-02308533 \\ https://hal.science/hal-02308533}

Submitted on 29 Jan 2020

HAL is a multi-disciplinary open access archive for the deposit and dissemination of scientific research documents, whether they are published or not. The documents may come from teaching and research institutions in France or abroad, or from public or private research centers.
L'archive ouverte pluridisciplinaire HAL, est destinée au dépôt et à la diffusion de documents scientifiques de niveau recherche, publiés ou non, émanant des établissements d'enseignement et de recherche français ou étrangers, des laboratoires publics ou privés. 
A New Electrochemical Cell with uniformly Accessible Electrode to Study Fast Catalytic Reactions

Mariam Fadel ${ }^{* 1,2}$, Jean-Vincent Daurelle ${ }^{* 1}$, Vincent Fourmond ${ }^{2}$, Jérôme Vicente ${ }^{1}$

${ }^{1}$ Laboratoire IUSTI (UMR AMU-CNRS 7343) Polytech Marseille, Dpt Mécanique Energétique (ME) Technopôle de Chateau Gombert 5 rue Enrico Fermi 13453 Marseille cedex 13

${ }^{2}$ Aix-Marseille Université, CNRS, BIP UMR 7281, 31 chemin J. Aiguier, F-13402 Marseille cedex 20, France

*Email : mariam.fadel@univ-amu.fr, jean-vincent.daurelle@univ-amu.fr

\begin{abstract}
Electrochemical study of fast catalytic reactions is limited by mass transport using the conventional electrochemical cell of Rotating disk electrode (RDE) [4]. To overcome this issue, it is important to find a new device with improved transport properties that is suitable for electrochemistry constrains.. We used numerical simulations of computational fluid dynamics to design a new electrochemical cell based on the so-called "jet flow" design for the kinetic studies of catalytic chemical reactions at the surface of an electrode. The new cell is characterized by a high, reliable and uniform mass transport over the electroactive part of its surface. We investigated the effects of the nozzle and the electrode diameters, the nozzle-electrode distance and the Reynolds number on the performance of the jet-electrode in the flow system. Through the optimization of the geometry of this jet electrode cell, we achieved a factor of 3 enhancement in transport compared to the Rotating disk electrode. We succeeded in constructing the designed electrode, characterized it using electrochemical techniques, and found excellent agreement between the transport properties deduced from the numerical simulations and those from the measurements.
\end{abstract}

Keywords: Jet flow Cell, Numerical Simulation, Mass Transport, Uniformly Accessible Electrode, Rotating Disk Electrode, Electrochemical Kinetic Studies

\title{
1. Introduction
}

Hydrodynamic electrodes are designed to provide well defined and reproducible mass transport rates. Electrochemists use widely hydrodynamic electrodes to enhance the transport of the chemical species to the surface of electrodes, for analytical or kinetic purposes. Here, we specifically focus on the 
application of hydrodynamic electrodes for the kinetic studies of enzymes immobilized on the surface of an electrode, a technique called Protein Film Voltammetry [1]. Rotating disk electrode is the mostly used hydrodynamic electrode for Protein Film Voltammetry, because of its simplicity, and also because it is a uniformly accessible electrode: the rate of transport is uniform across the electrode surface [2,3], even when taking into account the finite dimensions of actual electrodes [2]. Usually, the transport of the RDE is fast enough to prevent the depletion of the reactants in the vicinity of the electrode due to their consumption by the enzymatic reaction, which has allowed the mechanistic studies of many enzymes. However, some of us demonstrated recently that the transport afforded by the RDE is not fast enough for the study of some enzymes, called CO dehydrogenases, which catalyze the reversible oxidation of carbon monoxide [4]. Limitations by transport of the enzymatic substrate can obscure important features and complicate the quantitative analysis of the enzymatic response. This prompted us to look for another type of hydrodynamic electrode to build a new electrochemical cell with improved transport properties.

Flow cells based on imposing a flow by injecting or pumping the electrochemical buffer towards a stationary electrode have proved their capabilities for achieving rapid and effective transport. In this article, we specifically focus on the jet type electrode. The advantage of jet flows lies in a high, localized mass (or heat) transfer rate due to thin hydrodynamic and diffusion boundary layers within the stagnation region [5]. From the engineering point of interest, most of the studies on the literature focus on the transfer properties of the jet, and the variation of the general flow fields of submerged jets with the influence of the nozzle geometry [6,7], the depth of the liquid penetrated by the jet [8], the distance between the inlet and the electrode and the confinement of the volume entered by the jet [9]. Jet electrodes have been used for electrochemical studies, but this setup has not gained great popularity $[1,10]$, the RDE being by far the most commonly used hydrodynamic electrode $[1,11,12]$. However, the jet electrode have several advantages over the RDE: there is no rotating parts; the solution can be impelled through the jet by a pump or by gravity, the solution is flowed directly at the electrode, then the probability of having a dead zone is small [13].

The history of Jet electrode started from the middle of the $20^{\text {th }}$ century, first by Glauert in 1956 [14], that describes the term wall jet and the general view of the type of this flow. Based on that, Matsuda and Yamada in 1972, proposed a current formula for a jet solution issued from a circular nozzle normal to a disk electrode $[15,16]$. Their theoretical prediction of current reveals the dependence on the flow rate, the bulk concentration, the electrode and the nozzle diameter [15]. In 1978 Chin and Tsang, have suggested a new type of jet flow cell called "wall tube", in which the electrode surface is smaller than the nozzle, and proposed empirical current equation for this configuration [17]. Most of the studies focus on the geometrical properties and the volume flow rate ranges that fit with the desired application $[18,19]$. 
Other studies propose analytical solutions by neglecting the radial diffusion in order to compare with the other classical hydrodynamics electrodes [20-23]. Unwin and coworkers have tried to combine the advantages of the uniformly accessible electrode property of the wall tube electrode and the enhanced mass transport capacity of the ultra-microelectrode (of radius $\leq 25 \mu \mathrm{m}$ ), to construct so-called microjet electrodes and optimize their properties [24]. The consecutive studies [25-29] showed the capacity of these electrode to achieve high mass transport of chemical species at high applied velocities, on condition that the electrode is centrally aligned with the inlet, and at short electrode-nozzle distances (in the order $\mu \mathrm{m})$. However, these micro-jet electrodes are not practical for Protein Film Voltammetry, for several reasons. First, the enzymes are immobilized at the electrode surface [1], which, for most of the enzymes studied so far, is pyrolytic graphite "edge" $[1,30]$, which are not available at the very small dimensions required for microjet electrodes $(25 \mu \mathrm{m})$. Second, the high velocities used in the microjet to enhance the mass transport could negatively impact the stability of the enzyme layer on the electrode, since the increase in the velocity creates higher forces at the electrode (shear stress), which increases the washing effect on the enzymes. This is why we have chosen to work on jet electrodes with "macroscopic" dimensions comparable to those currently used for Protein Film Voltammetry.

There are rare studies concerning the optimization of the geometries of jet electrodes aimed for analytical applications. Laevers [18], described a new reactor based on a jet electrode for the quantitative electrochemical study of the mechanisms of AC electrolytic graining of aluminum substrates. Recently, Abro et al. [19] designed a new system with horizontal double impinging jet cells, and studied the flow modes for electrodeposition of composite/metal particle coating on the surfaces of two metal sheets. Ching and Tsang studied the variation of the transport-limited current with the flow rate (Reynolds number) and the chamber distance $Z$ (distance between the inlet and electrode surface) [17]. Moreover, they highlighted the influence of $\mathrm{Z}$ on the occurrence of instabilities that introduce laminar turbulent transition. However, none of these designs was aimed in their optimization for a uniform transport over the electrode, whereas a uniform transport is necessary for the quantitative interpretation of Protein Film Voltammetry data.

The complexity and the confusing variety in jet electrode configurations makes it hard to find a jet electrode suitable as a replacement of the RDE for the study of electron transfer and the mechanisms of the chemical processes. Furthermore, the designs of efficient jet flow cell are still rare, and the question of the uniformity of the transport is seldom addressed. We propose to overcome these limitations and design a new jet flow cell flow respecting these constraints, to be used in Protein Film Voltammetry experiments involving highly active enzymes [4]. In this paper, we start by simulating the response of the newly designed cell, showing the flow behavior at different flow rates, and we compare its performance 
with that of other jet electrodes. The second part presents the geometry optimization by understanding the dependence of the behavior of the mass transport with the geometrical parameters of the jet electrode: the nozzle-electrode diameter ratio and nozzle-electrode distance; we quantify the uniformity of the transport (local transport) over the electrode with the variable geometrical parameters. In the third part, we actually construct the experimental set-up corresponding to our new design, and determine experimentally the transport properties of the cell, showing the excellent agreement between the numerical and experimental results. We finish this study by comparing the mass transport and its homogeneity over electrode surface with the new electrochemical flow cell over the actual electrochemical of RDE, showing that for reasonable flow conditions, we gain a threefold increase in the transport rate compared to the RDE.

\section{The convective- Diffusion Equations: Wall-Jet and Wall Tube Electrodes}

In jet electrodes, the solution is impinged from a circular inlet (nozzle) positioned directly above the electrode (Figure 1). The nozzle is generally circular, but is sometimes rectangular [14]. The fluid which reaches the surface can only come from the incoming jet and not from any recirculation within the cell; this ensures that fresh incoming solution reaches the electrode continuously. The hydrodynamics of the wall-jet electrode (WJE) are considerably more complex than those of the channel or the rotating disc electrodes. The jet electrodes are classified into two types. The first is formally referred to as a 'wall-tube' [17], in which the electrode radius $(\mathrm{R})$ is smaller than the radius of the jet $(\mathrm{r} / \mathrm{R}>1)$. The second configuration is called 'wall-jet'[16] and corresponds to a jet smaller than the electrode radius $(\mathrm{r} / \mathrm{R}<1)$. The greatest impact of these two types of configurations is on the diffusion boundary layer, $\delta$, and the uniformity of the flux, J, at the electrode surface [3]. 


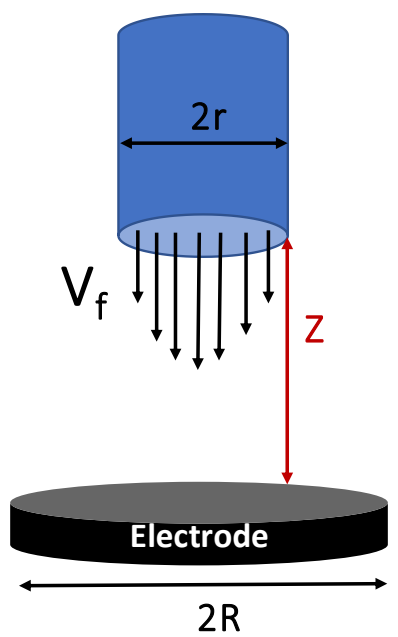

Figure 1: A schematic presentation of the geometrical parameters of a jet electrode: $r$ is the nozzle radius, $R$ is the electrode radius, $Z$ is the nozzle-electrode distance, $V_{f}$ is the volume flow rate. The electroactive surface is represented in a darker shade of gray.

The first formulation of hydrodynamics in the wall tube electrode (WTE) was attempted by Froessling using cylindrical coordinates [31]; then the power series were solved by Homann [31]. This was based on a model of a jet at a given volume flow rate $\left(\mathrm{V}_{\mathrm{f}}\right)$ impinging from a nozzle and travelling across the solution filled chamber at distance $Z$, before striking the electrode. The electrode is placed normal to the direction of the jet and flowing the solution away radially. The radial diffusion is neglected compared to the diffusion flux at the electrode.

Fick's law relates the surface flux of "a", $J_{a}$, to the gradient of mass fraction of species "a" at the electrode $(\mathrm{z}$ at electrode $=$ is $\mathrm{z}=0)$, where:

$$
\text { 1. } J_{a}=\rho D\left(\frac{\partial a}{\partial z}\right)_{z=0}
$$

Where $\mathrm{D}$ is the diffusion coefficient of the species, and $\rho$ is the density of the species. Considering that only species a is electroactive, the mass flux is related to the electrical current by the following equation:

$$
\text { 2. } J_{a}=I \rho / F A
$$

In which $\mathrm{I}$ is the current, $\mathrm{n}$ is the number of electrons involved in the reaction, $\mathrm{F}$ is the faraday constant $\left(96485{\mathrm{C} . \mathrm{mol}^{-1}}^{-1}\right), \mathrm{A}$ is the area of the electrode. 
The transport can be described as the continuous flow of the chemical species in the solution toward the electrode surface area, up to a certain level from the electrode surface. The reactants movements are controlled by diffusion (Figure 1), and this is computed by measuring the mass flux at the electrode. To avoid the depletion of the chemical species at the electrode when performing Protein Film Voltammetry experiments, the flow should be sufficiently fast to decrease the size of the diffusion boundary layer and enhance the mass transport. The diffusion boundary layer thickness, $\delta$, is related to the mass-transport-limited current $\left(\mathrm{I}_{\mathrm{lim}}\right)$ thus:

$$
\text { 3. } \delta=n F A D C_{b u l k} / I_{\text {lim }}
$$

The thickness of the boundary layer is dependent on the geometric parameters of the jetelectrode, mainly: the ratio of inlet-electrode diameter and the inlet-electrode distance, and also the flowrates. These parameters make it difficult to derive an analytical solution applicable to any jet electrode.

Ching and Tsang [17] proposed an empirical solution based on the experimental data. Equation 4 is the approximated solution of the current under laminar flow regime, for $\operatorname{Re}<2000,0.1$ $<\mathrm{R} / 2 \mathrm{r}<0.5$ and $0.1<\mathrm{r} / \mathrm{Z}<2.5$.

$$
\text { 4. } \quad I=0.61 F \pi D^{2 / 3} v^{-1 / 6} C_{b u l k} R^{2}\left(V_{f} / r^{3}\right)^{1 / 2}
$$

However, later studies showed contributions of five other parameter that are not included in this equation [25]: the thickness of the inlet walls [27], the presence and nature of vortices, the radial diffusion [25,26], the electrode-nozzle lateral position [26,32], and the inlet flow characteristics [25], which shows that equation 4 is only valid in very limited conditions.

\section{Numerical Simulation Method and Conditions}

To design a new geometry of enhanced and homogeneous mass transport device we modelized numerically many different electrochemical cells. In this paper, we present the optimization of the most promising cell, the wall tube with one inlet and two inclined outlets. All numerical simulations are performed with a finite volume method using the commercial software Starcem+ from CD adapco. We studied in a previous work the impact of the nozzle-electrode distance $Z$ on mass transport [33] for presented geometries in the literature, even though their concerns are for other different applications [34]. We propose a geometry based on jet flow in microfluidic bath as shown in Figure 2. The jet flow shape consists of an inlet of a nozzle close to the electrode surface, the nozzle-electrode distance is symbolized by $\mathrm{Z}$, the nozzle to electrode diameter ratio is 1 , an electrode support of diameter $L$ equals to $5 \mathrm{~mm}$. The 
flow exit is represented by two symmetric outlets at a short distance from the inlet $f$ equals to $1.8 \mathrm{~mm}$. Each outlet makes an angle of $26^{\circ}$ with the inlet, each with a diameter $r_{o}$ equals to $1.3 \mathrm{~mm}$. We chose these parameter considering literature sample [34,35], but also because of the machining limitations of the prototype Concerning the other dimensions, We discuss below the reason behind this selected configuration.

Jet flow shape is presented in Figure 2. Convection within the entire simulation domain is solved using the incompressible Navier-Stokes and continuity equations with the following boundary conditions:

Boundary 1 represents the inlet (nozzle) where the velocity is imposed, Boundary 2 the outlet section of the jet electrode. Boundary 3 is the electrode part. The boundary conditions are $C=0$ at $Z=0$ (electrode surface) and $\mathrm{C}=1$ corresponds to bulk solution for all other faces. A slip condition is applied at the upper free surface of the bath which remains flat.

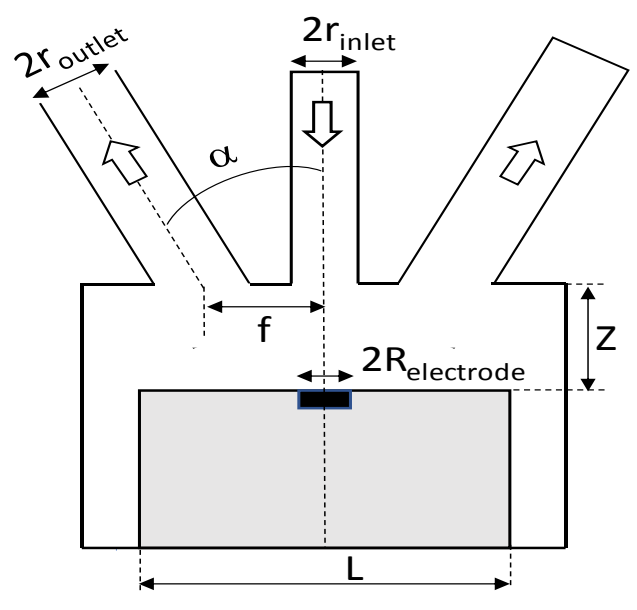

Figure 2: Geometric scheme of the inlet ( $r$ ) centered above the electrode of radius $R$ with two symmetric outlets $\left(r_{o}\right)$ aligned at angle $\alpha=26^{\circ}$ with the inlet, the chamber, $Z$, represents the distance between the inlet and electrode surface

The three-dimensional calculations were performed at a steady state flow regime, with a constant liquid density assuming a laminar flow with the following thermo-physical parameters; $\mathrm{H}_{2} \mathrm{O}$ at ambient temperature and pressure: density $=997.6 \mathrm{~kg} / \mathrm{m}^{3}$, dynamic viscosity, $\mu=8.8871 \times 10^{-4} \mathrm{~Pa}$.s and the diffusion coefficient of the chemical species used, $\mathrm{D}=1.25 \times 10^{-9} \mathrm{~m}^{2} / \mathrm{s}$, Schmidt number, Sc, $=709.2$.

To measure the performance of this electrode, we assume that the reaction rate at the surface is infinite, we apply a zero concentration on the electrode: $\mathrm{C}=0$ at $\mathrm{z}=0$, at the entrance of the nozzle we apply $\mathrm{C}=1$, and for all the other surfaces we apply a null flux. 
The laminar flow state is imposed based on the Reynolds number computed for tubular jet flow inlet, $\operatorname{Re}<2000$ for $\mathrm{V}<2 \mathrm{~m} / \mathrm{s}$, where $\mathrm{V}$ is the average velocity $(\mathrm{m} / \mathrm{s})$ of the fluid flow injected in the inlet, $\mathrm{D}$ is the diameter of inlet $(\mathrm{m})$ and $\mathbf{v}$ is the kinematic viscosity $\mathrm{m}^{2} / \mathrm{s}$ (equation 5 ). As the transition state from laminar flow to turbulent flow regime is greatly dependent on the cell configurations, it is unclear which is the critical Reynolds number in the Jet-electrode flow cell.

$$
\text { 5. } R e=D V / v
$$

Regarding the mesh conditions, the size of the mesh cells chosen tends to diminish while getting near the electrode surface (where the diffusion boundary layer is present), also with a fine mesh at the inlet of the chamber to ensure the good transition and avoid errors in the extracting data due to mesh defaults. Polyhedral mesh and prism layer models were used to achieve the discretization.

\section{Experimental Part}

We used a $\mathrm{NaCl}$ (from SIGMA Life Science) solution as an electrolyte at a concentration of 0.5 $\mathrm{mol} / \mathrm{L}$ and Mill-Q reagent water (Millipore Corp). Ferrocyanide solutions at a concentration of $1 \mathrm{mmol} / \mathrm{L}$ were prepared from potassium ferrocyanide (NORMAPUR from PROLABO) mixed with an electrolyte solution $(\mathrm{NaCl})$ of $0.5 \mathrm{~mol} / \mathrm{L}$ concentration.

To verify the mass transport coefficient to the new jet flow electrode system, measurements were carried at the graphite electrodes (circular, $1 \mathrm{~mm}$ diameter). These electrodes were positioned centrally downstream at the depth $370 \mu \mathrm{m}$ from the nozzle surface by the use of calibrating spacer. The flow was imposed using a peristaltic pump (DRP-PPUMP from Metrohm) in a closed loop system that was made oxygen-free by bubbling argon into the main reservoir. All experiments were conducted at room temperature (approximately $298 \pm 1 \mathrm{~K}$ ).

\section{Results and Discussions}

\subsection{Flow Regime Description}

The 3D finite volume simulations were run at several velocities, to study the flow behavior at different Reynolds number. The diffusion process is controlled by the flow behavior. The flow around the electrode is completely conditioned by the geometry of the cell.

Figure 3 shows that the velocity field is well established in the inlet tube. It hits the electrode (the electroactive surface) and diffuses radially out from the electrode and then the flow exits symmetrically 
from the two outlets. This explains our choice to place two outlets symmetrically aligned and inclined, to get a good homogeneity of flow in the cell chamber. The flow behavior is much more homogeneous than previous designs with only one outlet $[33,34]$. Considering the good performance of the two outlet cells, we do not present the three or four outlet devices simulations, which did not yield a significant improvement in terms of homogeneity (data not shown).

We represent in Figure 3, the flow behavior at low Reynolds number $(\mathrm{Re}=20$, velocity $0.02 \mathrm{~m} / \mathrm{s}$, volume flow rate $\left(V_{\mathrm{f}}\right)=1 \mathrm{ml} / \mathrm{min}$ ) (Figure 3-(a)) and at high Reynolds number ( $\mathrm{Re}=800$, average velocity, $\mathrm{v}=0.8 \mathrm{~m} / \mathrm{s}$ ) (Figure 3-(b)). The flow behavior is consistent at the different tested velocities. To investigate the impact of the nozzle to electrode diameter ratio, preserving the characteristic of the Wall-tube electrode of $r / R \geq 1$, we perform a comparable numerical simulation at same $R e=400$, where $r / R=1$ and $\mathrm{r} / \mathrm{R}=2$ with $\mathrm{r}=0.5 \mathrm{~mm}, \mathrm{Z}=0.37 \mathrm{~mm}(\mathrm{Z} / \mathrm{r}=0.74)$ and the velocity profiles are shown in Figure 3-(c and $\mathrm{d})$ respectively. In both cases the flow shows symmetric behavior. However, in the first case at low velocity, the flow is maximum toward the center of the electrode then turns to decrease slightly while moving along the electrode surface and getting away from the outlet. On contrary for the second case, the flow is lowest toward the center of the electrode and shows an extreme near the end part area of the electrode. This indicates the impact of accelerating the flow is evident to decrease the dead zone, while producing higher mass flux at the electrode surface. This is quantified below (Figure 4). The thin chamber, short electrode- inlet distance, shows its strength in providing a confined flow avoiding the formation of recirculation and vortex inside. The flow profile presented here demonstrates a well-defined flow moving radially as the fluid is moving out from the nozzle toward the outlets. The fluid velocity is initially low near the center of the electrode and increases as moving along the electrode, producing a true symmetric uniform radial flow. At higher velocities, the fluid speed shows highest velocities as the fluid leaves the nozzle opening to the chamber, creates a higher flow near the electrode surface which will be collated to the variation and the increase of the mass flux at this part of the electrode. The breakdown of the symmetric flow occurs near the outlet sections. Importantly, the distortion of the radial flow occurs sufficiently far away from the electrode that the flow at the electrode can still be considered symmetric. The uniform radial flow within a confined geometry of two symmetric inclined outlets supports the value of this design providing a confined flow, preventing the formation of recirculation and vortices. 
(a)
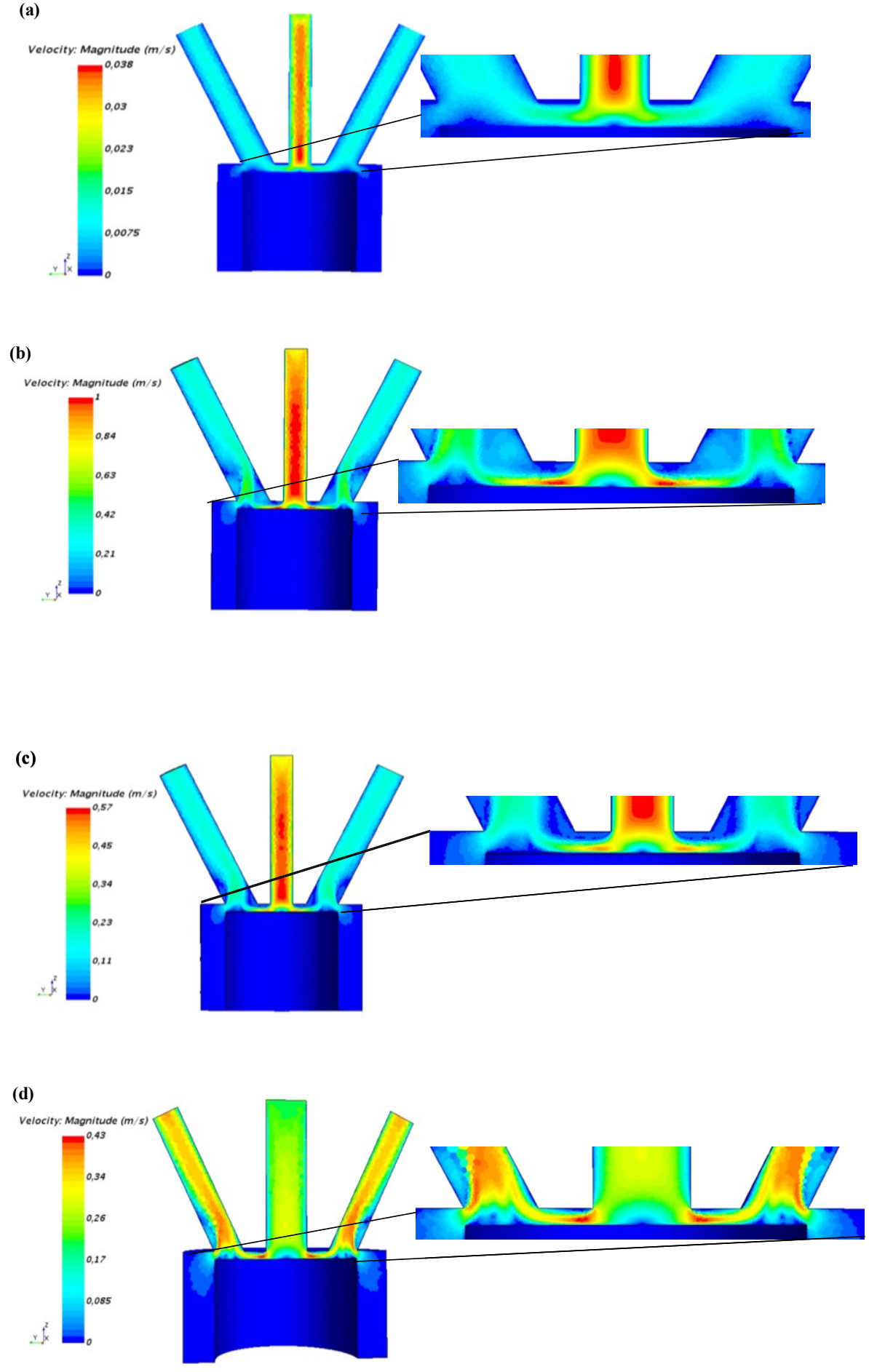

Figure 3:The numerical simulations predict the hydrodynamic profile for the flow in the system of new designed flow cell. The velocity magnitude through the system is presented: (a) at volume flow rate $1 \mathrm{ml} . \mathrm{min}^{-1}$ corresponds to the average velocity $0.02 \mathrm{~m} / \mathrm{s}, R e=20$; (b) at higher flow rate of $37.6 \mathrm{ml}^{\mathrm{min}} \mathrm{m}^{-1}$ corresponds to velocity of $0.8 \mathrm{~m} / \mathrm{s}, R e=800$; (c) at $R e=400$, and (d) at $R e=400$ for the case of bigger inlet $r=2 r$, nozzle to electrode diameter ratio $(r / R)$ equals to 2. Inset: a zoom or the part of flow leaving the inlet directly toward the electrode surface. 


\subsection{Uniformly accessible electrode}

We show in the previous section, the qualitative influence of the Re and of the nozzle to electrode radius ratio $(\mathrm{Re}, \mathrm{r} / \mathrm{R})$ on the structure of the flow in vicinity of electrode. To go beyond the qualitative analysis of the behavior of the flow, we must quantitatively determine the transport properties of the electrodes. In particular, we want to check that the electrode is "Uniformly accessible", which means that the mass flux of the electroactive species is uniform over the electrode surface [3].

We plot the mass flux along the diameter of the electrode surface (Figure 4(a)). We choose to plot the flux along the diameter perpendicular to the outlet plane because it is the least homogeneous profile. Clearly, the results show a homogeneous symmetric distribution of the flux at the electrode surface, with at most $12 \%$ variation along the electrode diameter for $r / R=1$. However, for $r / R=2$, the electrode loses part of this uniformity, and the variation of the flux along the electrode raises to $18 \%$ as shown in Figure 4(C). It is important to highlight the symmetric behavior of the flow reaching the electrode surface in the boundary layer presented by the homogeneous flux distribution at the electrode surface, this is related to the symmetric position of the outlets with the electrode.

To understand more quantitatively the small variation of the flux distribution at the electrode, we plot the axial velocities along the electrode surface (Figure 4(B)). At low Reynolds, $R e=20$ the flux is high at the center and tends to decrease along the electrode radius. This is correlated to the higher axial velocity at the center and the decrease in this velocity at the middle position and at the end of the electrode radius. This behavior changes at higher Reynolds numbers, the axial velocity is lowest at the center and tends to increase along the electrode radius. This behavior creates a lowest flux at the center and then increases the flux toward the electrode radius. These variations reveal that the system at the lowest Reynolds numbers is still close to diffusive configuration, whereas at higher Reynolds numbers the flow is more constrained with this geometric configuration and generates higher flux at the electrode edges (Figure 3).

The homogeneous flux reflects the homogeneity of diffusion boundary layer near the electrode

and characterizes the electrode as a "uniformly accessible" as shown in 
(a)

Figure . The flux field of the

(a)

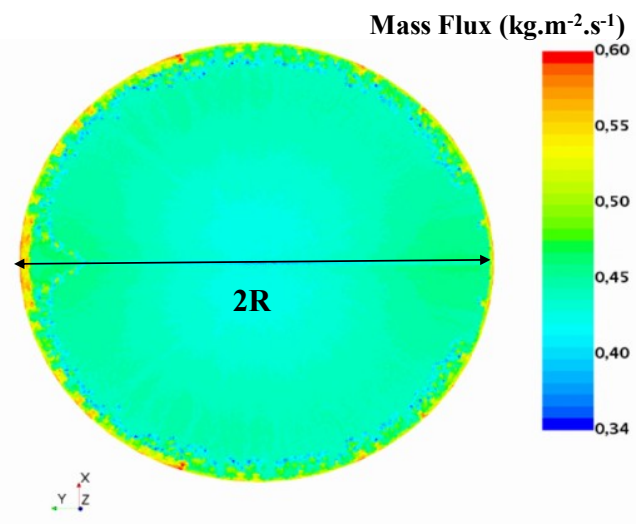

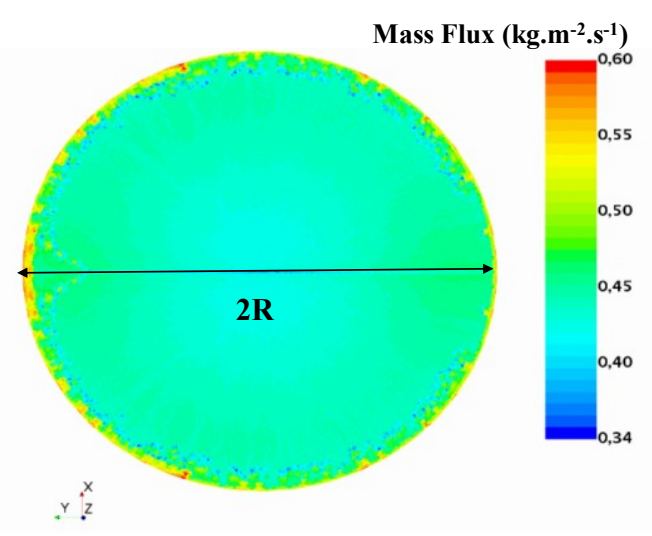

(b)

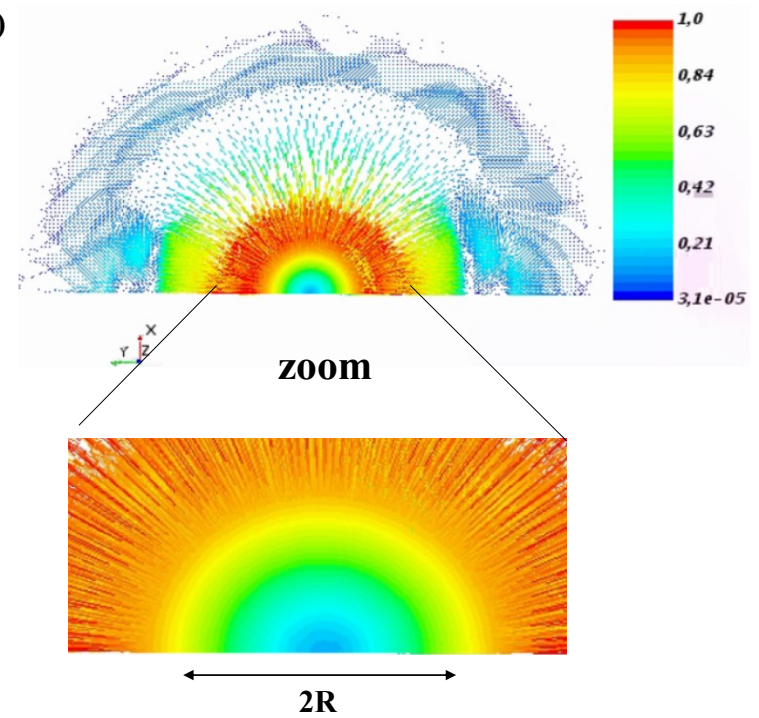

Velocity $\left({\left.\mathrm{m} . \mathrm{s}^{-1}\right)}^{-1}\right.$

electrode surface at $\mathrm{Re}=800$ is shown in

(b) Velocity $\left({\left.\mathrm{m} . \mathrm{s}^{-1}\right)}^{-1}\right.$

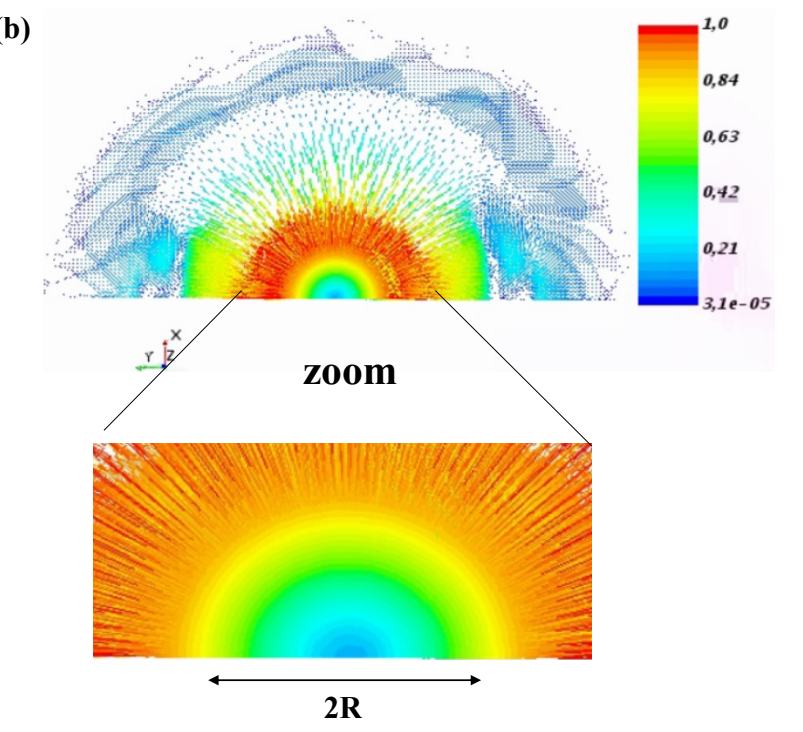

Figure -a. It confirms the symmetric and homogenous distribution of the flux over the electrode. This is explained by the symmetric flow behavior represented by the velocity vector field shown in the 
(a)

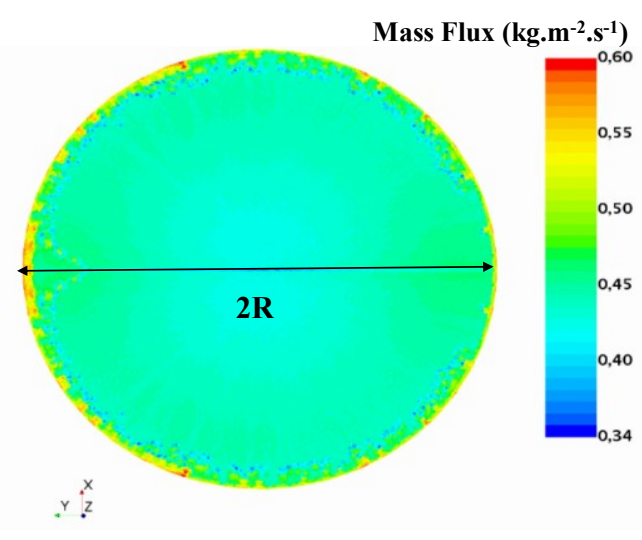

(b)

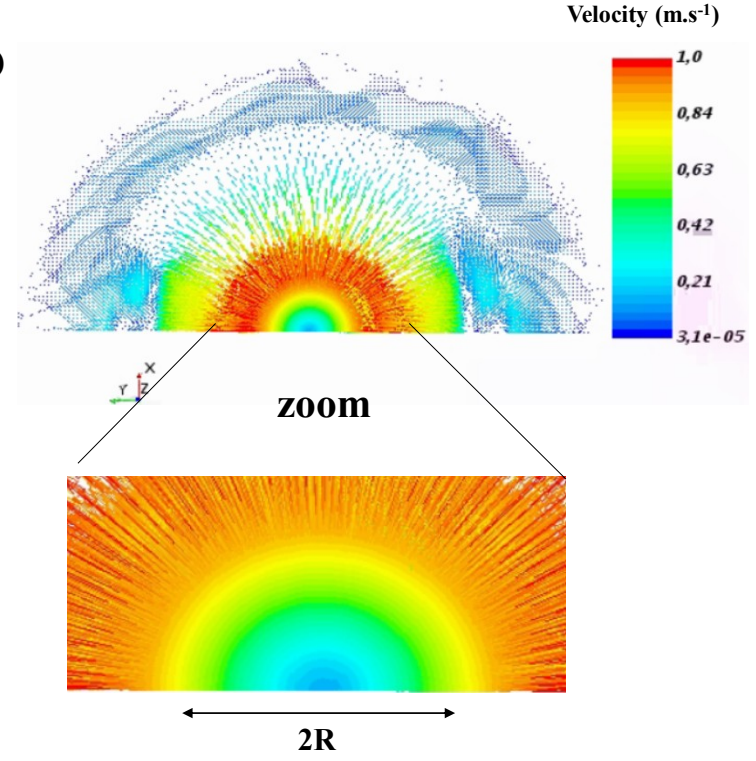

Figure $-\mathbf{b}$, on a plane parallel to the electrode surface. An inset magnifies the vectors field to illustrate the symmetric and uniformity of the flow in the boundary layer. 

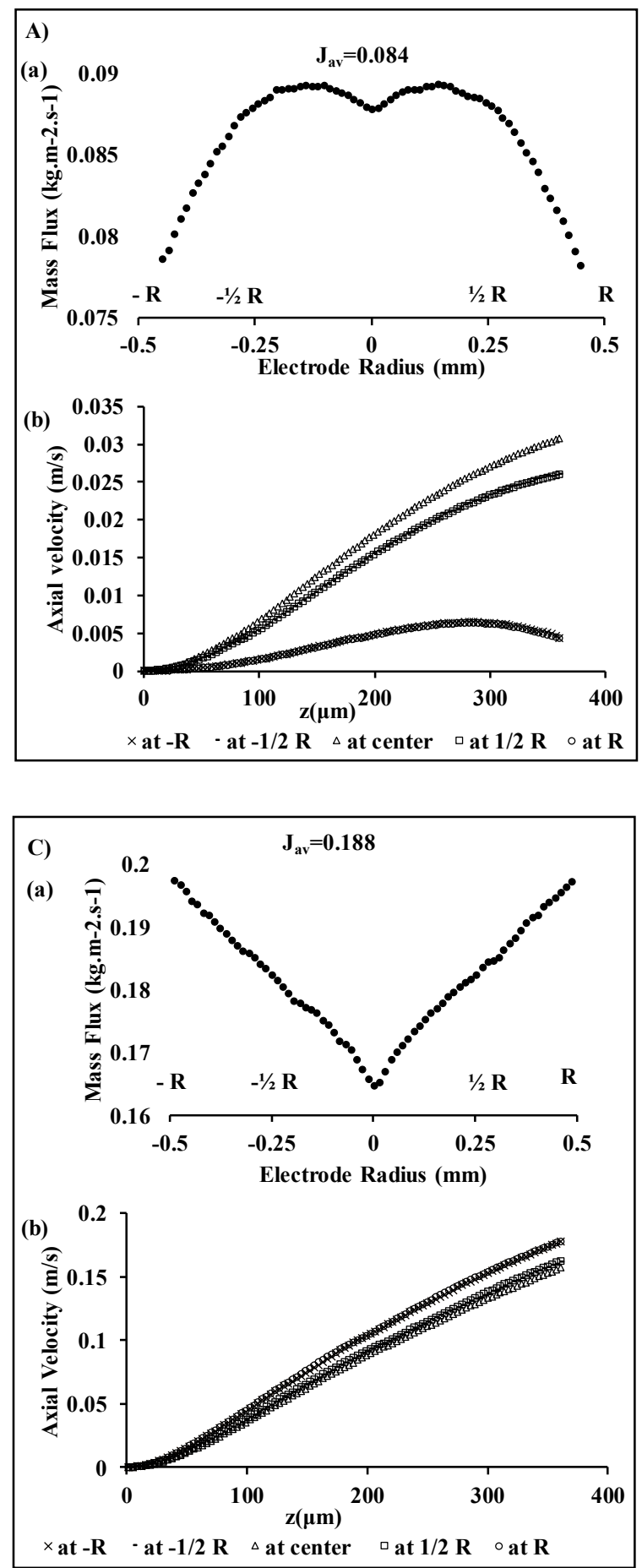

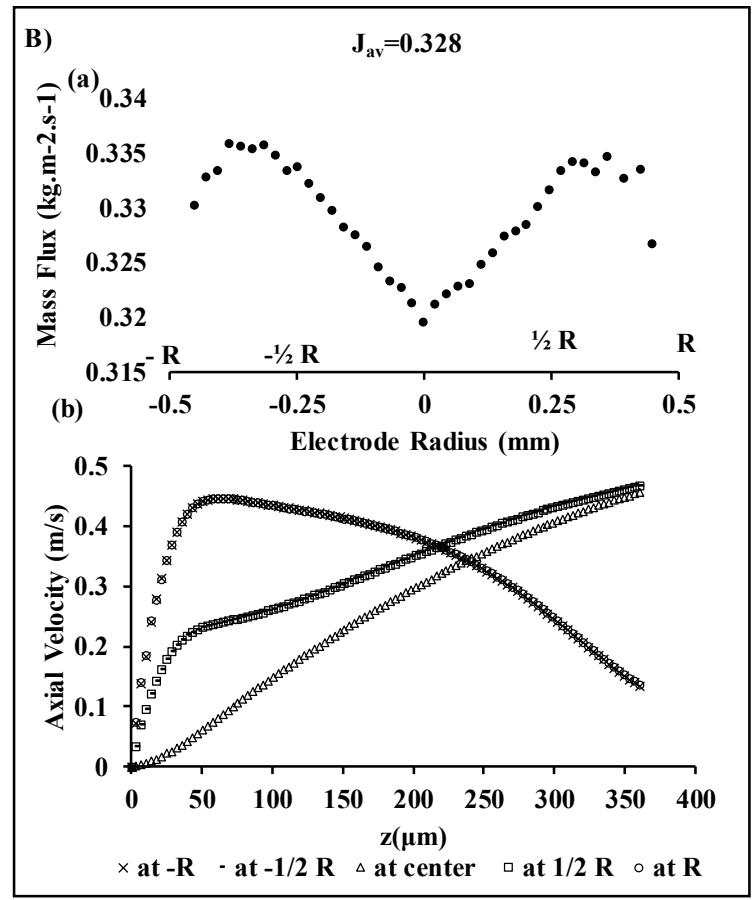

Figure 4: Comparison of the flux behavior at low and high velocities of the (a) axial velocities with the compatibility of (b) the mass flux profiles at the electrode: A) at low velocity, B) at high velocity, and $C)$ for the case of diameter of the inlet is 2 times bigger $(r / R=2)$. 
(a)

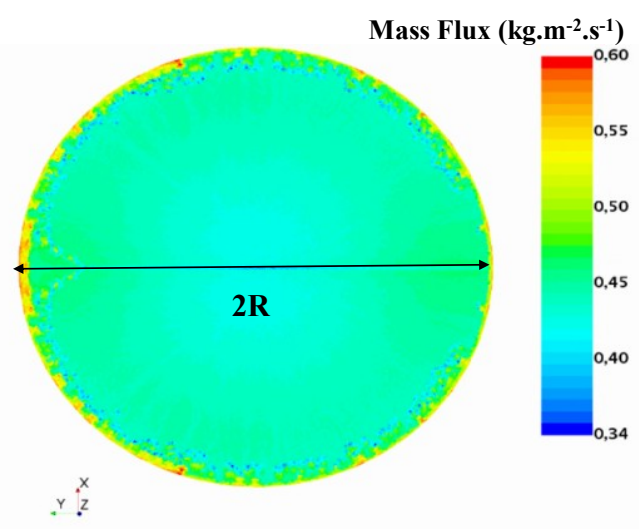

(b)

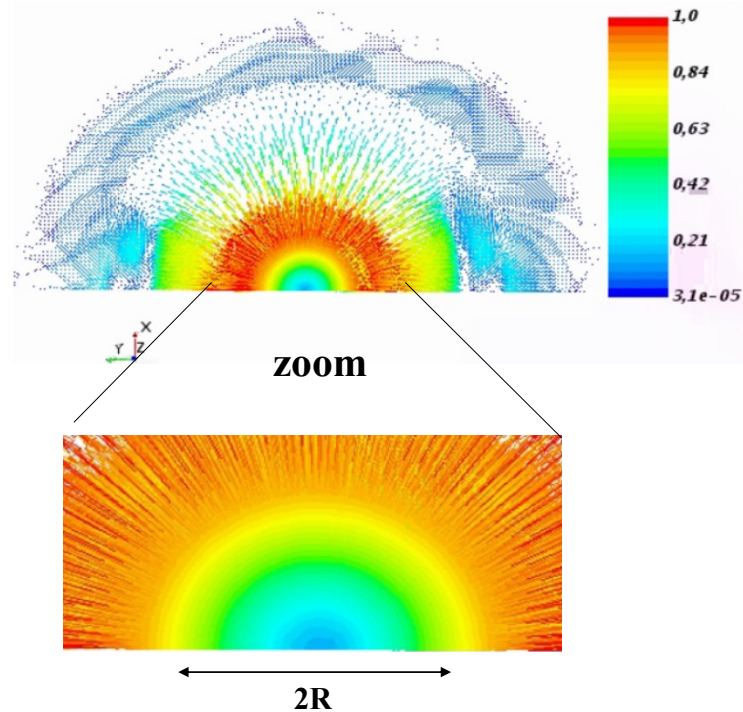

Figure : a) Mass flux at electrode surface, and b) Velocity vectors at a plane parallel the electrode at distance of $\mathrm{mm}$ with zoom on electrode area. This numerical result corresponds for the $r_{T} / R=1$, $Z / r_{T}=0.74, R e=800$.

To compare the homogeneity of the flux over the electrode surface at different Reynolds numbers, we plot the dimensionless flux $\varphi:\left(\mathrm{j} / \mathrm{j}^{*}\right.$, in which $\mathrm{j}^{*}$ is the average surface flux), along the radius of the electrode at different Reynolds numbers (Figure 5). The lowest variation is reached for $\mathrm{Re}=400$. It can be called the critical Reynolds number for the best uniformity of the flux. The ratio ranges between 0.94-1.06, which shows the uniformity of the transport achieved with this design.

At this critical Reynolds number, we plot the ratio of the flux for a bigger nozzle diameter ( 2 times bigger, $r / R=2$ ) at same boundary conditions. This ratio ranges between 0.87 and 1.05 , which indicates a loss of uniformity of the flux. Thus, extending the nozzle diameter to a bigger size than the electrode leads in our configuration to a less homogenous transport. The positive impact of the peripheral part of the jet have seen on the previous configuration is, with a bigger nozzle, out of the electrode active part (Figure 3-d). It seems that, to get the fastest and most homogeneous transport to the electrode the nozzle radius should be equal to the electrode radius $(\mathrm{r} / \mathrm{R}=1)$. 


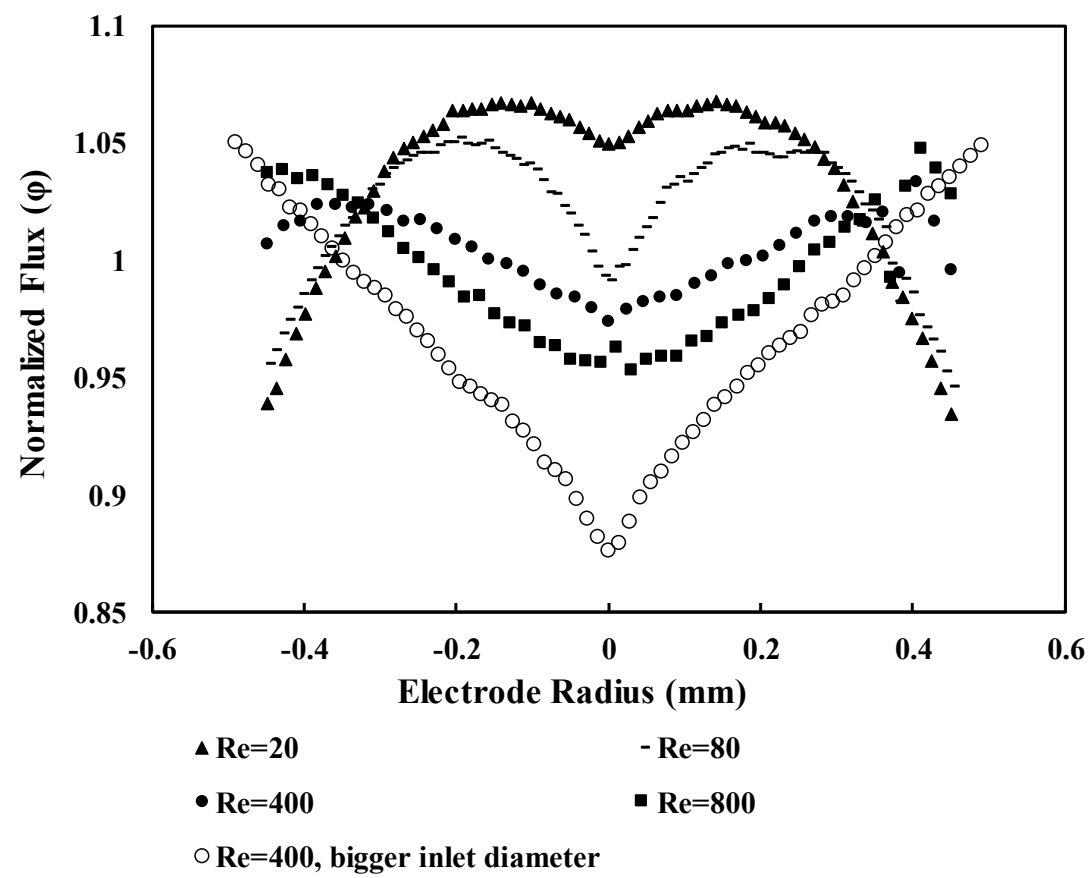

Figure 5:The evolution of the normalized flux, $\varphi$, (the ratio between the mass flux, $j$, and the average flux $j^{*}$ ) at the electrode surface with the variation of the velocity inside the cell represented by the Reynolds number Re.

\subsection{The impact of the jet electrode-nozzle distance on the efficiency and the homogeneity of the mass transport at different Reynolds number}

The main advantage of the Rotating Disk Electrode is that the mass flow at electrode can be controlled very precisely with the rotation velocity. It is very important to determine the factors governing this mass flow in our cell and so to predict the flow behavior with Reynolds number under laminar conditions. We ran simulations in the range of $20 \leq \operatorname{Re} \leq 800$ and determined the parameters of transport from the simulations. The increase in the velocity of the flow leads to an increase in the flux towards the electrode surface.

One of the parameters that plays an essential role on the structure of the flow around the electrode and then in the efficiency of the setup is the nozzle-electrode distance. The increase in the distance plays part in the laminar-turbulence transition, that is barely described in the literature [19,36]. Figure 6-A shows the variation of the mass Flux at different ratios of nozzle-electrode distance ' $Z$ ' to the ' $r$ ', with the variation of the Reynolds number. The Ratio of $\mathrm{Z} / \mathrm{r}$ ranges from 0.3 to 3 . The increase in the velocity 
results an increase in the flux at the different nozzle-electrode no distance. In this graph we also add the empirical equation [3] (equation 4) that resembles the expression of the flux of a $\operatorname{RDE}[12,37,38]$.

Our numerical results (Figure 6 -A) show a tendency in good agreement with that of equation 4 of Chin and Tsang $[3,17]$ with the $\mathrm{Z} / \mathrm{r}=0.4$ case. We observe a difference for the lowest Reynolds. Previous studies have already shown differences with the Chin and Tsang model [3]. They explained this difference by the fluid properties [25], or very specific geometries [26,39].

For all Reynolds numbers, the configuration with closest nozzle to electrode distance shows the best mass flux (Figure $6 \mathrm{~A}$ ). Furthermore, all the configuration of $\mathrm{Z} / \mathrm{r}$ ratio follow the same variation of Mass flux with the Reynolds number thus with the inlet volume flow rate. This means that regardless of the ratio we use in our device, we can expect to control the mass flux with the volume flow rate.

In Figure $6 \mathrm{~B}$, at different ratios of $\mathrm{Z} / \mathrm{r}$, we plot the variation of the mass transport coefficient $(\mathrm{m}=\mathrm{D} / \delta)$, which is proportional to the flux, in other words the heterogeneity, at the Reynolds number 800 . From this graph, we can distinguish between two regions that meet at the critical $\mathrm{Z} / \mathrm{r}=0.74$. In the first region $(\mathrm{Z} / \mathrm{r}<0.74)$, where the mass transport is large the heterogeneity is the highest, it reaches $37 \%$ at $\mathrm{Z} / \mathrm{r}=0.3$.

In the second region, where $\mathrm{Z} / \mathrm{r}>0.74$, the best uniformity of the mass transport is reached. But the mass transport has lower value and become constant after $Z / r=0.74$. This result show similarities with the study of the impact of impinging jet for thermal application, which concludes that the highest heat transfer coefficient at a determined ratio of Z/r [6]Thus, as a good compromise between uniformity and mass transport, we choose to optimize our system at $\mathrm{Z} / \mathrm{r}=0.74$. 

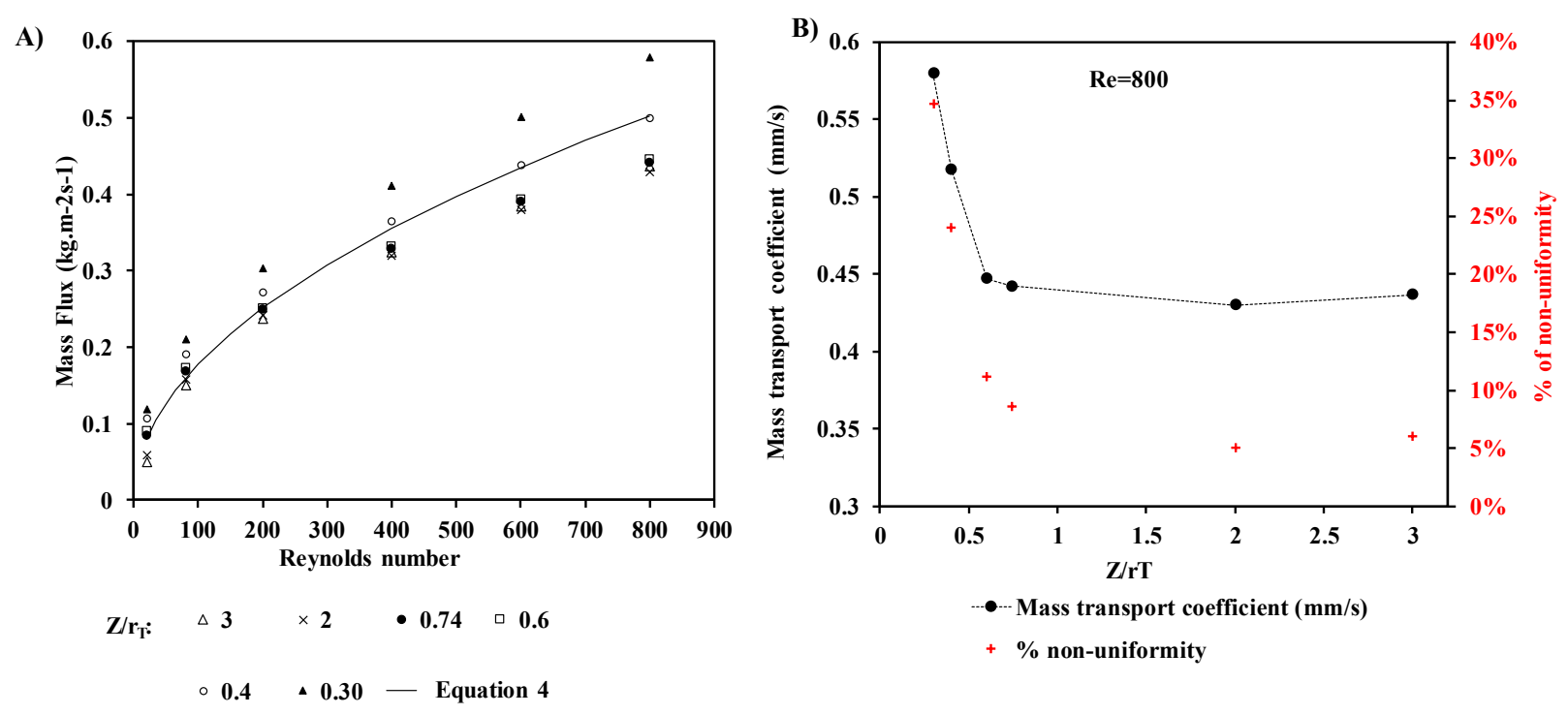

Figure 6: Variation of Mass flux with the Reynolds number for different nozzle-electrode distance ' $Z$ ', which ranges from $0.2 \mathrm{~mm}$ to $1.5 \mathrm{~mm}$, presented as the ratio of $Z$ by the nozzle radius $r,(Z / r)$, and $B)$ represents the plot of the variation of the mass transport coefficient and the \% of the uniformity with the variation of the ratio of $Z / r$ at Reynolds number 800 .

\section{Experimental Investigations of the Performance of the New Designed Cell}

We built the designed cell by assembling two parts. The bottom part was machined using traditional workshop techniques, and hosts the three electrodes as shown in Figure 7. The working electrode is encased in an epoxy shell. The reference is an $\mathrm{Ag} / \mathrm{AgCl}$ wire, and the counter electrode is a platinum wire. To make it easier to change the geometry of the cell, the top part, which includes the inlet and the outlets was printed using stereolithography (Figure $7 \mathrm{~A}$ and B); this allows for easy changes in the configuration of the flow (position of the inlet/outlets, nozzle to electrode distance, etc), because all one needs to change the parameters is to print a new upper part. The two cells are assembled using screws, and waterproofed using a large toric joint (Figure $7 \mathrm{C}$ and D). 
A

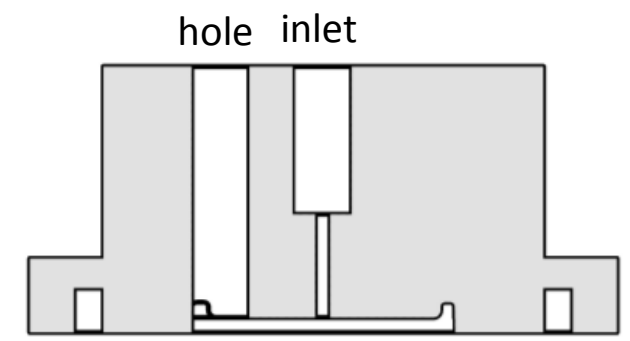

C
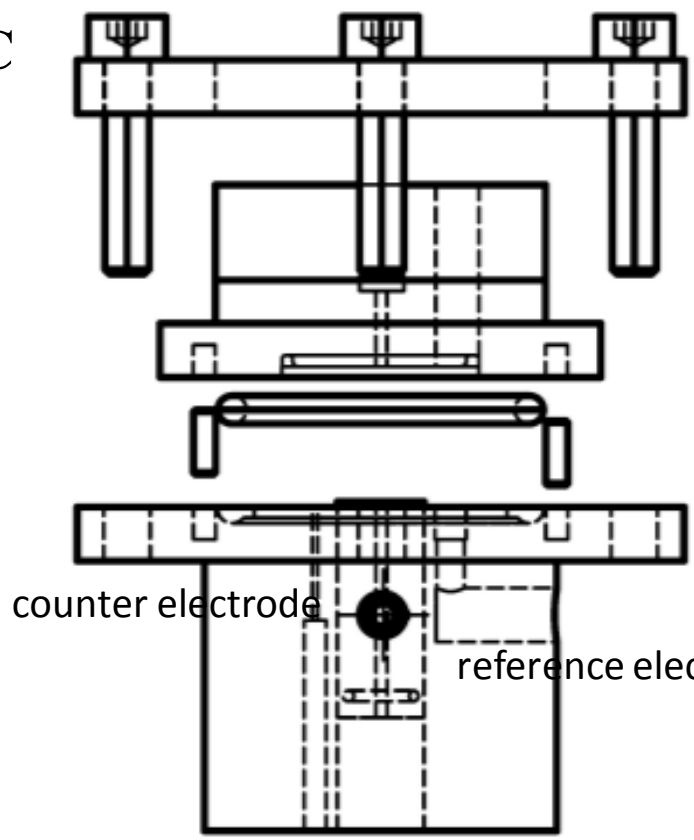

B

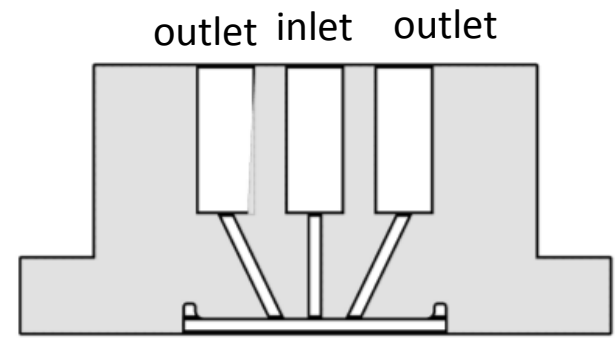

D
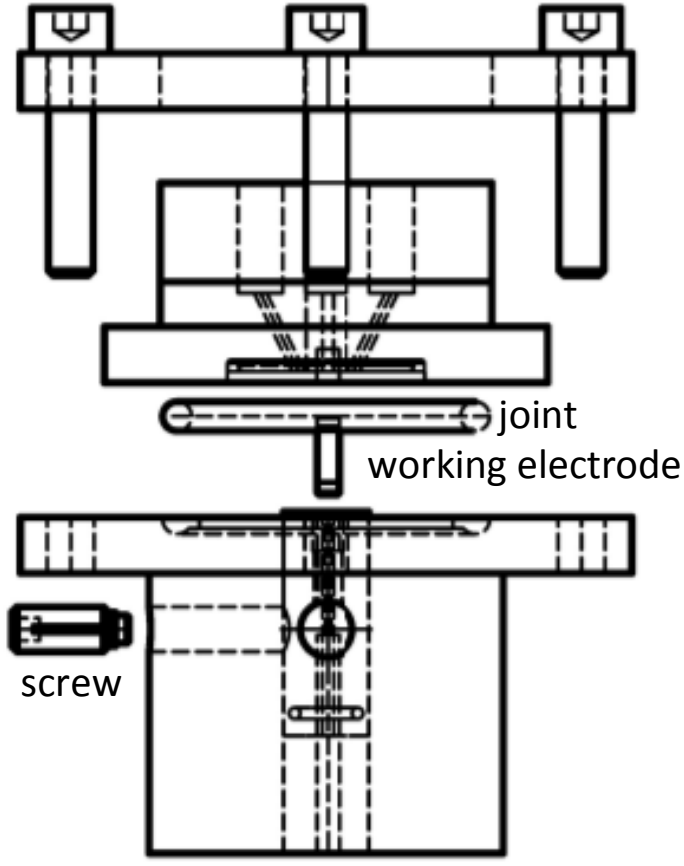

$0 \quad 4 \mathrm{~mm}$

Figure 7: The design of new jet cell : (a) is the view along the upper part of the cell to show the hole, (B) is the view along the upper part of the cell that includes the inlet and two symmetric outlets, $(C)$ is the view of the two assembly parts of the cell along the side that shows the part of the reference electrode $(R E)$ and counter electrode (CE), and (D) is the view of the tow assembly parts of the cell the working electrode (WE) and the screw that fix it.

We first proceeded to measure the diffusion coefficient of $\mathrm{Fe}\left(\mathrm{CN}_{6}\right)^{3-} / \mathrm{Fe}\left(\mathrm{CN}_{6}\right)^{4-}$ redox couple with this setup. We chose to determine the diffusion coefficient using cyclic voltammetry in the absence of flow in order to be under the same conditions as for the experiments under flow. We performed diffusive cyclic voltammetry experiments at the electrode in the absence of flow at several scan rates between $10 \mathrm{mV} / \mathrm{s}$ and $100 \mathrm{mV} / \mathrm{s}$. The resulting curves are shown in the Figure 8-A. They display the usual behavior of a quasi-reversible redox couple with a reduction peak on the scan towards low potentials followed by a re-oxidation peak on the reverse scan. The curves have similar shapes at all scan 
rates. The linear dependence of the peak current as a function of the square root of the scan rate (Figure 8B) shows that, in the absence of flow, the cell behaves exactly like a traditional stationary electrode.
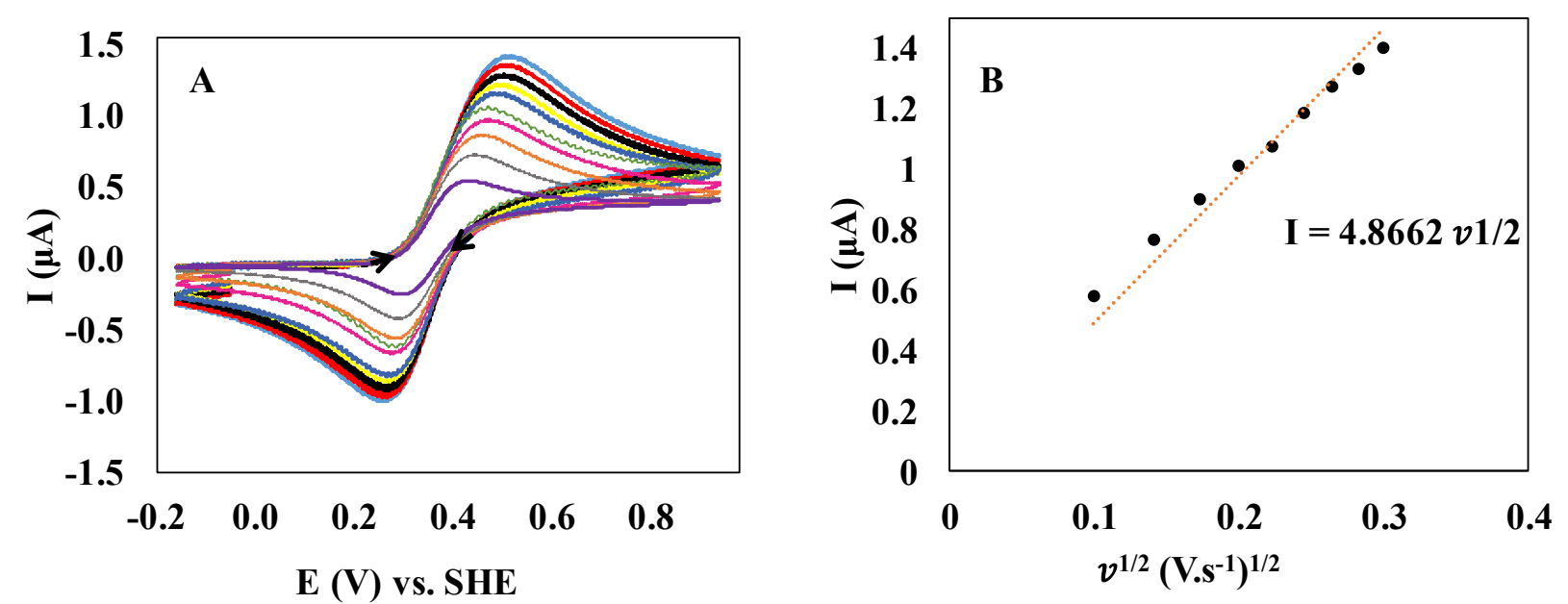

$\begin{array}{rrr}-100 \mathrm{mV} / \mathrm{s} & -90 \mathrm{mV} / \mathrm{s} & -80 \mathrm{mV} / \mathrm{s} \\ 70 \mathrm{mV} / \mathrm{s} & -60 \mathrm{mV} / \mathrm{s} & -50 \mathrm{mV} / \mathrm{s} \\ -40 \mathrm{mV} / \mathrm{s} & -30 \mathrm{mV} / \mathrm{s} & -20 \mathrm{mV} / \mathrm{s} \\ -10 \mathrm{mV} / \mathrm{s} & & \end{array}$

Figure 8: (A) Cyclic voltammograms of the $(1 \mathrm{mM}) \mathrm{Fe}\left(\mathrm{CN}_{6}\right)^{3-} / \mathrm{Fe}\left(\mathrm{CN}_{6}\right)^{4}$ in an electrolyte of $0.5 \mathrm{M} \mathrm{NaCl}$ at a range of scan rates $(10 \mathrm{mV} / \mathrm{s}$ t0 $100 \mathrm{mV} / \mathrm{s})$, and (B) Peak current as a function of scan rate, with the linear relationship (dotted line). The experiments were conducted at room temperature.

For a quasi-reversible couple, we expect the peak currents to be related to the scan rate by the following equation [37], where $\mathrm{A}\left(\mathrm{cm}^{2}\right), \mathrm{D}\left(\mathrm{cm}^{2} / \mathrm{s}\right), \mathrm{C}\left(\mathrm{mol} / \mathrm{cm}^{3}\right)$ and $v(\mathrm{~V} / \mathrm{s})$.

$$
\text { 6. } \quad I=269000 C A D^{1 / 2} v^{1 / 2}
$$

Using (equation 6) on the data of Figure 8-B, we calculated a diffusion coefficient for the redox couple $\mathrm{Fe}\left(\mathrm{CN}_{6}\right)^{3-} / \mathrm{Fe}\left(\mathrm{CN}_{6}\right)^{4-}$, of $\mathrm{D}=5.6 \times 10^{-6} \mathrm{~cm}^{2} / \mathrm{s}$ which is compatible with the values available in the literature $[40,41]$

We then proceeded to determine the mass transport coefficient $m$ for different values of the flow rate. Figure 9 A shows the cyclic voltammograms for the reduction of $1 \mathrm{mM}$ of $\mathrm{Fe}\left(\mathrm{CN}_{6}\right)^{3-}$ in $0.5 \mathrm{M}$ of $\mathrm{NaCl}$ at $50 \mathrm{mV} . \mathrm{s}^{-1}$ under flow conditions, for various flow rates. The voltammograms are typical of steady-state hydrodynamic electrodes, and show a plateau current at low potentials, whose magnitude increases with the flow rate. . The oscillations visible in the plateau currents in figure 10 arise from fluctuations in the flow induced by the use of a peristaltic 
pump, as is attested by the fact that the frequency of the oscillations is proportional to the pump rotation rate. These fluctuations do not affect the measure of the average current (corresponding to the average flow measured by the flowmeter).
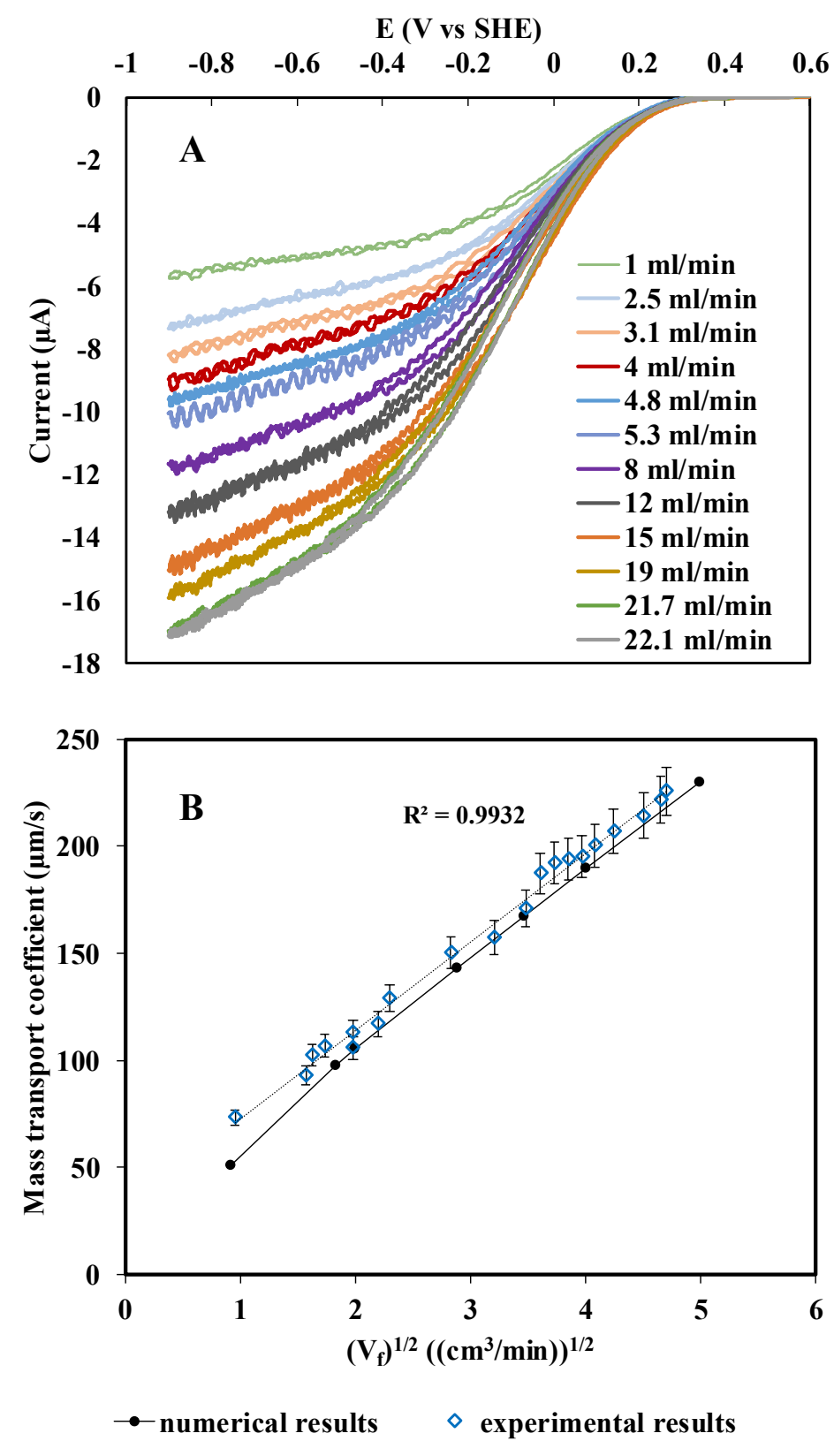

Figure 9: Experimental determination of the transport properties of the new electrochemical cell: A) Cyclic voltammetry for the reduction of $\mathrm{Fe}\left(\mathrm{CN}_{6}\right)^{3-}(1 \mathrm{mM})$ in an electrolyte solution of $0.5 \mathrm{M} \mathrm{NaCl}$ at a graphite electrode of diameter $1 \mathrm{~mm}$ at $50 \mathrm{mV} \cdot \mathrm{s}^{-1}$. The experiments are conducted at volume flow rate of range $(1 \mathrm{ml} / \mathrm{min}$ to $37 \mathrm{ml} / \mathrm{min})$ using peristaltic pump at performed at room temperature, under degassed system with argon. B) Comparison of the mass transport coefficient $(m=I / n F A)$ extracted from the cyclic 
voltammetry experiments of reduction of $\mathrm{Fe}\left(\mathrm{CN}_{6}\right)^{3-}$ with the numerical simulation results, $\mathrm{D}=5.6 \times 10^{-6}$ $m^{2} \cdot s^{-1}$.

Figure $9 \mathrm{~B}$ shows the mass transport coefficient calculated from the numerical simulations (in black line) versus the experimental mass transport coefficient extracted from the experimental limiting current from Figure $9 \mathrm{~A}$ (the maximum current), in open squares for the $\mathrm{Fe}\left(\mathrm{CN}_{6}\right)^{3-} / \mathrm{Fe}\left(\mathrm{CN}_{6}\right)^{4-}$ redox couple. The mass transport coefficient is calculated based on the relation between the mass transport coefficient, $m$, and the limiting current, $I$, according to equation 7 .

$$
\text { 7. } m=I / F A C
$$

Where $\mathrm{A}$ is the electrode area (of radius $500 \mu \mathrm{m}$ ), $\mathrm{F}$ is the Faraday constant, and $\mathrm{C}$ is the concentration of the solution used (1 mMolar).

As can be seen in Figure $9 \mathrm{~B}$, there is an excellent agreement between the experimentally measured mass transport coefficients (determined from the limiting current) and those predicted from the numerical simulation, up to $\mathrm{V}_{\mathrm{f}}$ values of $25 \mathrm{ml} / \mathrm{min}$. It is important to note that under highest volume flow rate conditions the cell did not leak, which is the main disturbances and can be an obstacle during the experimental work. The experimental data fully support the numerical simulations. Note that the two parts of the jet cell can easily reconnected without the need for re-calibration of cell dimensions after cell assembly, and easily reconnect the electrode to be polished and cleaned up. This cell design should be compatible with most types of electrode materials [42].

\section{Enhancement of the transport: Comparison with the "RDE" cell}

The recent study of the highly active enzymes that catalyzes the reversible reduction of carbon dioxide (Carbon-monoxide dehydrogenase), shows limitations in transport when adsorbed onto a rotating disk electrode [1,4,11]. This is a hindrance for the quantitative analysis of kinetic data [4], and greatly complexifies the study of this enzyme using RDE. We plot in Figure 10, the mass transport of our newly designed cell as a function of the Reynolds number, together with the one of the RDE at 5000 r.p.m (Figure 10). This rotation rate is the maximum practically applicable rotation used during the experiments, since higher rotation rate, vibrations and instabilities in the solution bath compromises the experiments. Figure 10 shows a significant enhancement of the transport in the new designed over that of the $\mathrm{RDE}$, since the mass transport rate is 3 times higher at a Reynolds number of 800 (of $\mathrm{V}_{f}=37.5$ $\mathrm{ml} / \mathrm{min}$ ), which is easily achievable experimentally. With this new cell design, it is enough to run the 
system at $3.7 \mathrm{ml} . \mathrm{min}^{-1,} \mathrm{Re}=80$, to get the same mass transport rate at a high rotation (5000 r.p.m) of RDE. Furthermore, compared to other geometries cell we get a good enhancement in transport without exceeding 800 Reynolds, which guarantee the laminar flow regime in the cell without disturbances and instabilities. We could enhance the mass transport by raising the velocity higher, but this may lead to a washing of enzymes. We have no knowledge of this washing effect which is not treated in literature. This concern will be investigated experimentally with the prototype based on the enzyme characteristics.

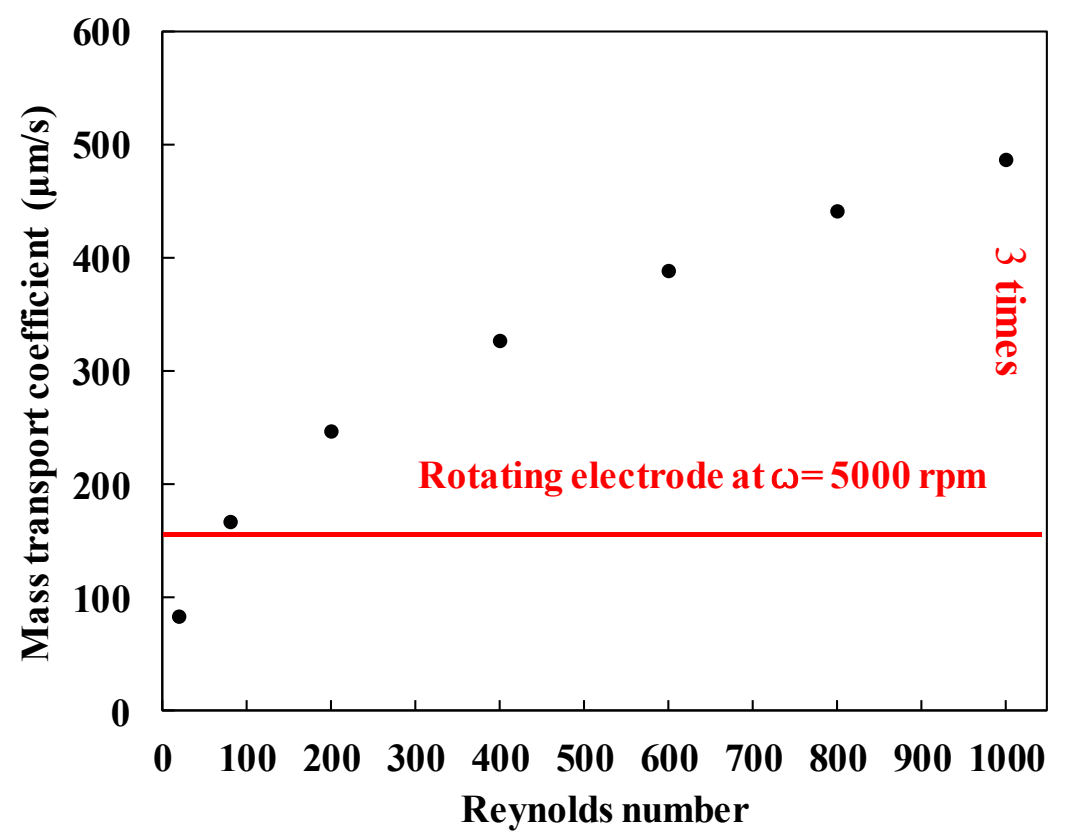

Figure 10: Comparison of the transport in the two different geometries: horizontal line corresponds to $R D E$ at maximum reliable rotation rate $5000 \mathrm{rpm}$ corresponds to Re $=3500$, the closed circle symbol corresponds to the numerical results of the new designed jet cell.

\section{Conclusions}

The goal of this study was to overcome the mass transport limitations of the RDE by a new design of flow jet-electrode and determine its range of use. This study consisted in the design and hydrodynamic characterization of the electrochemical jet cell. We investigated the impact of the nozzleelectrode distance, the ratio of nozzle to electrode diameter and the Reynolds number on the performance of this jet -cell. We optimized the parameters and we find that the ratio of $r / R=1$ with a $\mathrm{Z} / \mathrm{r}<2$, are best to achieve the highest and homogeneous mass transport toward the electrode with a reasonable range of Reynolds numbers. This design of wall-tube jet flow cell could be used to replace the classical RDE by improving the mass transport by more than three times and preserving the homogeneity of the flux at the 
electroactive part of the electrode. The properties of this optimized cell will make it possible to study rapid kinetic reactions of highly active catalysts We have now to optimize and adapt the facilities of our cell, pump; flow meter, valves, etc. to introduce and use them in a glove box in order to study the enzymes as CO dehydrogenase..

\section{Acknowledgements}

We gratefully acknowledge the financial support from Ecoles doctorales of Sciences pour l'ingenieur and science chimiques from Aix-Marseille University for the funding of the thesis of MF. The authors acknowledge financial support from CNRS, Agence Nationale de la Recherche (ANR-14-CE050010, ANR-15-CE05-0020, ANR-17-CE11-002), and Région PACA. The project leading to this publication has received funding from Excellence Initiative of Aix-Marseille University - A*Midex, a French "Investissements d'Avenir" programme. MF and VF are members of the French Bioinorganic Chemistry group (http://frenchbic.cnrs.fr). The authors are also thankful to CD-ADAPCO for Star CCM+.

\section{References}

[1] C. Léger, P. Bertrand, Direct Electrochemistry of Redox Enzymes as a Tool for Mechanistic Studies Direct Electrochemistry of Redox Enzymes as a Tool for Mechanistic Studies, Chem. Rev. 108 (2008) 2379-2438.

[2] M. Fadel, J.-V. Daurelle, J. Vicente, V. Fourmond, Impact of alignment defects of rotating disk electrode on transport properties, Electrochim. Acta. 269 (2018) 534-543.

[3] W.J. Albery, S. Bruckenstein, Uniformly accessible electrodes, J. Electroanal. Chem. Interfacial Electrochem. 144 (1983) 105-112.

[4] M. Merrouch, J. Hadj-Saïd, C. Léger, S. Dementin, V. Fourmond, Reliable estimation of the kinetic parameters of redox enzymes by taking into account mass transport towards rotating electrodes in protein film voltammetry experiments, Electrochim. Acta. 245 (2017) 1059-1064.

[5] M. Chen, R. Chalupa, A.C. West, V. Modi, High Schmidt mass transfer in a laminar impinging slot jet flow, Int. J. Heat Mass Transf. 43 (2000) 3907-3915.

[6] S. Garimella, Nozzle-geometry effects in liquid jet impingement heat transfer, Int. J. Heat Mass Transf. 39 (1996) 2915-2923.

[7] M.R. Samuels, D.M. Wetzel, Velocity profiles in the exit region of a submerged laminar jet, 
Chem. Eng. J. 4 (1972) 41-45.

[8] J. Kuang, C.-T. Hsu, H. Qiu, Experiments on Vertical Turbulent Plane Jets in Water of Finite Depth, J. Eng. Mech. 127 (2001).

[9] S. V. Garimella, V.P. Schroeder, Local Heat Transfer Distributions in Confined Multiple Air Jet Impingement, J. Electron. Packag. 123 (2001) 165.

[10] K.; Stulik, V. Pacakova, Electroanalytical Measurements in Flowing Liquids, John Wiley and Sons,New York, NY, 1987.

[11] V. Fourmond, C. Léger, Protein Electrochemistry: Questions and Answers, in: Biophotoelectrochemistry From Bioelectrochemistry to Biophotovoltaics. Adv. Biochem. Eng., Springer, Cham, 2016: p. 41.

[12] V. Levich, Physicochemical hydrodynamics., Prentice-Hall, Englewood Cliffs N.J., 1962.

[13] W.J. Albery, C.M.A. Brett, THE WALL-JET RING-DISC ELECTRODE PART I. THEORY, J Electroanal Chem. 148 (1983) 201-210.

[14] M.B. Glauert, The wall jet, J. Fluid Mech. 1 (1956) 625.

[15] H. Matsuda, J. Yamada, Limiting diffusion currents in hydrodynamic voltammetry: I. Fixed disk and ring electrodes in laminar uniform flow, J. Electroanal. Chem. Interfacial Electrochem. 30 (1971) 261-270.

[16] J. Yamada, H. Matsuda, Limiting diffusion currents in hydrodynamic voltammetry: III. Wall jet electrodes, J. Electroanal. Chem. Interfacial Electrochem. 44 (1973) 189-198.

[17] D.-T. Chin, C.-H.J. Tsang, Mass transfer to an impingning electrode, Electrochem. Soc. 125 (1978) 1461.

[18] P. Laevers, A. Hubin, H. Terryn, J. Vereecken, A wall-jet electrode reactor and its application to the study of electrode reaction mechanisms Part I : Design and construction, J. Appl. Electrochem. 25 (1995) 1017.

[19] D.M.K. Abro, P. Dable, F. Cortez-salazar, V. Amstutz, E.K. Kwa-koffi, H. Girault, Design and Characterization of a Horizontal Double Impinging Jet Cell : Determination of Flow Modes at the Surface of a Flat Electrode, J. Mater. Sci. Chem. Eng. (2016) 18-28.

[20] R.G. Compton, A.C. Fisher, M.H. Latham, R.G. Wellington, C.M.A. Brett, A.M.C.F.O. Brett, Wall jet electrodes: the importance of radial diffusion, J. Appl. Electrochem. 23 (1993) 98-102. 
[21] R.G. Compton, A.C. Fisher, G.P. Tyley, Nonuniform Accessibility and the Use of Hydrodynamic Electrodes for Mechanistic Studies - a Comparison of Wall-Jet and Rotating-Disk Electrodes, J. Appl. Electrochem. 21 (1991) 295-300.

[22] I. Streeter, R.G. Compton, Steady state voltammetry at non-uniformly accessible electrodes: a study of Tafel plots for microdisc and tubular flow electrodes in the reversible and irreversible limits of electron transfer., Phys. Chem. Chem. Phys. 9 (2007) 862-70.

[23] N. Rees, R. Compton, Hydrodynamic microelectrode voltammetry, Russ. J. Electrochem. 44 (2008) 368-389.

[24] J. V Macpherson, S. Marcar, P.R. Unwin, Microjet Electrode: A Hydrodynamic Ultramicroelectrode with High Mass-Transfer Rates, Anal.Chem. 66 (1994) 2175-2179.

[25] N. V. Rees, O. V. Klymenko, B. a. Coles, R.G. Compton, Hydrodynamics and Mass Transport in Wall-Tube and Microjet Electrodes: An Experimental Evaluation of Current Theory, J. Phys. Chem. B. 107 (2003) 13649-13660.

[26] J.L. Melville, B.A. Coles, R.G. Compton, N. Simjee, J. V. Macpherson, P.R. Unwin, Hydrodynamics and mass transport in wall tube and microjet electrodes. Simulation and experiment for micrometer-scale electrodes, J. Phys. Chem. B. 107 (2003) 379-386.

[27] J.L. Melville, N. Simjee, P.R. Unwin, B.A. Coles, R.G. Compton, Hydrodynamics and mass transport in wall tube and microjet electrodes: Effect of vortex formation and cell geometry on limiting currents, J. Phys. Chem. B. 106 (2002) 10424-10431.

[28] J. V Macpherson, M.A. Beeston, P.R. Unwin, Imaging Local Mass-transfer Rates within an Impinging Jet and Studies of Fast Heterogeneous Electron-transfer Kinetics using the Microjet Electrode, J. CHEM. SOC. FARADAY TRANS. 91 (1995) 899-904.

[29] E. Bitziou, N.C. Rudd, M.A. Edwards, P.R. Unwin, Visualization and modeling of the hydrodynamics of an impinging microjet, Anal. Chem. 78 (2006) 1435-1443.

[30] C.E. Banks, R.G. Compton, New electrodes for old: from carbon nanotubes to edge plane pyrolytic graphite, Analyst. 131 (2006) 15-21.

[31] D.H. Schlichting, K. Gersten, Boundary-layer theory, Eur. J. Mech. - B/Fluids. 20 (1979) 817.

[32] J. V. Macpherson, M.A. Beeston, P.R. Unwin, N.P. Hughes, D. Littlewood, Imaging the Action of Fluid Flow Blocking Agents on Dentinal Surfaces Using a Scanning Electrochemical Microscope, 
Langmuir. 11 (1995) 3959-3963.

[33] M. Fadel, J. Daurelle, V. Fourmond, Enhancing Mass Transport in Jet Electrode to Study Highly Active Enzymes, Congrés Fr. Mech. (2017) 1-10.

[34] M.E. Snowden, Electroanalytical Applications of Carbon Electrodes using Novel Hydrodynamic Flow Devices, 2010.

[35] N. Kulyk, S. Cherevko, M. Auinger, C. Laska, K.J.J. Mayrhofer, Numerical Simulation of an Electrochemical Flow Cell with V-Shape Channel Geometry, 162 (2015) 860-866.

[36] C.F. Ma, Y. Zhuang, S.C. Lee, T. Gomi, Impingement heat transfer and recovery effect with submerged jets of large Prandtl number liquid-II. Initially laminar confined slot jets, Int. J. Heat Mass Transf. 40 (1997) 1491-1500.

[37] A.J. Bard, L.R. Faulkner, electrochemical methods fundemental and applications, second edi, 2001.

[38] R.G. Compton, C.E. Banks, Understanding Voltammetry, (2011).

[39] J. Melville, N. Simjee, P.R. Unwin, B.A. Coles, R.G. Compton, Hydrodynamics and Mass Transport in Wall Tube and Microjet Electrodes . 1 . Finite Element Simulations, J. Phys. Chem. B. (2002) 2690-2698.

[40] W. Bellagha-Chenchah, C. Sella, L. Thouin, Understanding Mass Transport at Channel Microband Electrodes: Influence of Confined Space under Stagnant Conditions, Electrochim. Acta. 202 (2016) 122-130.

[41] C. Amatore, S. Szunerits, L. Thouin, Mapping concentration profiles within the diffusion layer of an electrode Part II. Potentiometric measurements with an ultramicroelectrode, Electrochem. Commun. 2 (2000) 248-253.

[42] M.E. Snowden, P.H. King, J.A. Covington, J. V. MacPherson, P.R. Unwin, Fabrication of versatile channel flow cells for quantitative electroanalysis using prototyping, Anal. Chem. 82 (2010) 3124-3131. 